\title{
Clinical Competencies in Advanced Practice Respiratory Therapy Education: Is It Time to Entrust the Learner?
}

This article was published in the following Dove Press journal:

Advances in Medical Education and Practice

\author{
Abdullah Alismail $\mathbb{D}^{1,2, *}$ \\ David López ${ }^{1, *}$ \\ 'Department of Cardiopulmonary \\ Sciences, School of Allied Health \\ Professions, Loma Linda University, Loma \\ Linda, CA, USA; ${ }^{2}$ Department of \\ Medicine, Loma Linda University, Loma \\ Linda, CA, USA \\ *Both authors contributed equally to this \\ work
}

Correspondence: Abdullah Alismail

Department of Cardiopulmonary

Sciences, School of Allied Health

Professions, Loma Linda University, Loma

Linda, CA 92354, USA

Email aalismail@llu.edu

\begin{abstract}
The field of clinical education in health care has undergone several paradigm shifts in regards to its original theoretical frameworks across multiple healthcare professions. One of the most common evaluation and assessment tools undergoing equal amounts of change and research is competency-based education. In that vein, the respiratory care profession is also experiencing similar challenges to better asses and evaluate clinical competency. One of the emerging professional directions in respiratory care is the establishment of the advanced practice respiratory therapist (APRT) at the graduate level. This new advanced degree profession currently relies on competencybased education as an evaluation and assessment framework to fulfill the competency domains required by the professions accrediting agency, the Commission on Accreditation for Respiratory Care (CoARC). Since advanced practice, respiratory therapists will be considered advanced practice providers, a more robust assessment tool should be considered to assess and evaluate their clinical performance. The purpose of this article is to establish a higher evaluation and assessment framework, the Entrustable Professional Activity (EPA) tool. Entrusting the learner to be competent practitioners involves many aspects of practice skills, tasks, and other intangible areas such as behaviors and critical thinking that may not typically part of a competency-based education framework. We thus propose a sample EPA framework that is aligned with current CoARC APRT core competencies and a recommendation for an implementation strategy to assist the respiratory care community at large. Keywords: advanced practice respiratory therapy, competency, entrustable professional activities
\end{abstract}

\section{Introduction}

Respiratory care is currently undergoing a major shift as a profession, with the emergence of the advanced practice respiratory therapist (APRT) concept. According to the American Association in Respiratory Care (AARC) and the Commission on Accreditation for Respiratory Care (CoARC):

APRT is a trained, credentialed, and licensed respiratory care practitioner who is employed to provide a scope of practice that exceeds that of the registered respiratory therapist. ${ }^{1,2}$

Not only does this new direction in professional practice require a higher level of education, it also establishes a higher level of autonomy and responsibility. Thus, the scope of practice of the APRT implied in the CoARC Practice Standards outlines a scope of practice of advanced practice providers similar to those of physician assistants (PAs), nurse practitioners (NPs), or radiology assistants (RAs), and certified nurse anesthetists (CRNA). The APRT, will practice in the 
critical care, and physician clinics, as well as cardiopulmonary rehabilitation centers, home care setting, etc. Each clinical rotation, therefore will have their respective competencies provided for each clinical practice setting that meets CoARC core competencies. And as such, it is expected that an APRT will be called upon to examine, treat patients, have prescriptive authority with certain medications, order diagnostic tests, diagnoses, and counsel patients in various settings, working with healthcare personal, across the healthcare spectrum under the leadership of a physician. ${ }^{2}$ As mentioned above, the change in practice would include not only advanced knowledge and skills, but those of limited prescription authority, diagnostic prescription, and diagnosis of patients not currently part of respiratory practice.

The movement towards the APRT profession is not only supported by the AARC and CoARC, it is also endorsed by the American College of Chest Physicians and the American Thoracic Society, and is supported by the American Society of Anesthesiologists included in the opening statement of the CoARC, Accreditation Standards report for Advanced Practice Programs in Respiratory Care. $^{3}$ This added level of physician support enhances and provides valuable opportunities to collaborate and share best practices in clinical practice outcomes.

With the above collaboration and support, the respiratory care profession made the decision to move forward in establishing the advanced practice provider, APRT, and appropriate fact finding and needs assessment. In 2015 Keene et $\mathrm{al}^{4}$ investigated the perception of current respiratory therapists (practitioners, educators, and managers) regarding the concept of APRT or advanced practice providers. In their findings among the 506 respondents, 234 were educators. The respondents' level of education was as follows: $31.7 \%$ held an associated degree, and $31.7 \%$ held a bachelor's with the remainder holding a master's degree. When respondents were questioned regarding the required or preferred hours for an APRT programs clinical training, they reported the following: 500 (21.4\%), 750 (34.5\%), 1000 (31.4\%), >1000 (12.4\%). An additional study by Douce, Sergakis, Dunlevy, Varekojis ${ }^{5}$ in the state of Ohio, a majority of practitioners and students showed interest in an advanced clinical program at the master's degree level for the advanced respiratory therapy practitioner. This finding was consistent with the study of Keene, McHenry, Byington, Washam $^{4}$ where respondents also indicated a preference for a minimum master's degree level of education for an APRT. Douce, Sergakis, Dunlevy, Varekojis ${ }^{5}$ article served in part, of a needs assessment towards the development of an advanced clinical master's of respiratory therapy program in Ohio. These are examples of the communities of interest regarding the development and acceptance of the concept of physician extender profession like the APRT. It is also understood that regulatory and reimbursement issues at the state level, and federal level will further define and direct the future of the APRT across the United States. However, with the support of the respiratory care professional organization, accrediting agencies, and the profession's communities of interest, it is now time to consider the best assessment and evaluation tools that can be utilized in examining the efficacy and success of an APRT graduate from a clinical practice perspective. The concept of an entrusted learner is a new concept that can and should be included in the future education and development in this new emerging profession in respiratory care.

The purpose of this perspective article is to discuss the concept of EPA in the area of evaluation and assessment of clinical competencies in APRT education future graduates.

\section{Overview of Clinical Education}

Clinical education typically involves one-on-one teaching at the bedside. This concept evolved from the apprenticeship model used by the Greeks in or about 500 B.C. ${ }^{6}$ The use of such models have evolved in many ways over time, especially in health profession education, with a major paradigm shift following the release of Abraham Flexner's report on medical education in and William Osler contributions on the importance of bedside practice. $^{7-9}$

Medicine is learned by the bedside and not in the classroom. Let not your conceptions of manifestation of disease come from the words heard in the lecture room or read from the book. See and then reason and compare and control. But see first. [Osler; ${ }^{8}$ page 114]

Both of these frameworks established the foundation for most, if not all, health profession education programs in the United States to date, in addition to the apprenticeship model. ${ }^{9}$ From these models or frameworks, the assessment and evaluation model that is mostly used are competencies in selected areas of practice and skill sets in each profession using the Competency-Based framework. ${ }^{10-13}$

The concept of competency-based education (CBE) was established in the 1900s. At the time, businesses were looking for methods to "standardize" workers' knowledge and skills. ${ }^{10,11}$ In the United States alone there are approximately 600 institutions that utilized competency-based education as an 
educational model. ${ }^{11}$ When viewing CBE closely, it has evolved through different phases from 1910 to the present through: innovative faculty development programs, vocational programs, and current advanced technology such as online learning and other teaching and learning strategies. ${ }^{11}$ Since its introduction, there have been challenges to the CBE framework in relation to evaluation and assessment in that it leans more towards formative assessment rather than a summative outcome of practice, thereby potentially lacking defined outcomes. ${ }^{12,14}$

The challenges above may be seen in the respiratory care profession that has competency-based standards and guidelines from the COARC at the Registered Respiratory Therapists (RRT) entry level. The CoARC, on the other hand has included advanced higher-level competencies not currently performed by the entry-level RT, that are delineated as six APRT core competencies a graduate should achieve: 1) respiratory care knowledge, 2) interpersonal and communication skills, 3) patient care, 4) professionalism, 5) systems-based practice, 6) and inter-professional practice (CoARC APRT accreditation standards, pp. 32-36). ${ }^{3}$ The structure of these competency domains is left to individual programs to structure in terms of learning objectives, teaching models, assessments, learning outcomes, and evaluations. The results of this process are that a graduate of one program will likely have different learning objectives and evaluation methods in any or all of these core competencies as outcomes to clinical practice.

Although each program will most likely have their own formative and summative assessment tools or criteria to meet the core CoARC competencies for the APRT, assessment, in general, should not end there. ${ }^{12}$ How can and at what point can a clinical educator assure that the student can be "trusted" to successfully perform competencies as a professional in all domains post-graduation? The word "trusted" should be considered a higher-level hierarchy assessment and evaluation concept, more than only achieving a specific competency based on individual learning objectives in the program at one point in time. Basically, how many times must a competency be met until an evaluation is made that the student can be trusted to practice or treat any given procedure or task independently? The spectrum of care of the advanced practice provider encompasses more than the evaluation and assessment of an individual skill. This spectrum of care includes, but is not limited to, the physical exam, ordering diagnostic tests, prescribing medications, diagnosing, counseling and educating patients, and managing this entire process with the health care team. Therefore, trusting an individual to perform specific clinical skills or diagnoses should require more than just spending a specific number of clocked clinical hours or performing a specific skill multiple times, especially for an advanced practice healthcare provider. Our goal and aims should be expanded more to a higher level, to "trust" the learner to practice independently. Thus, the following section will introduce a conceptual theoretical framework, EPA, that has been adapted in other health care fields under the umbrella of "clinical education." This framework addresses how to translate competencies into clinical practice to attain trust from a perspective of performing a complete task that involves many possible procedures in patient care as described above. ${ }^{15}$

\section{Entrustable Professional Activities}

In 2005 , ten Cate ${ }^{16}$ introduced the Entrustable Professional Activity (EPA) to the medical health profession education community. EPAs can be defined as:

[...] units of professional practice, defined as tasks or responsibilities to be entrusted to the unsupervised execution by a trainee $[\ldots] .{ }^{15}$

The process of developing EPAs can be described as follows: "as an educator/assessor/supervisor, will you be able to 'trust' the learner to execute this skill independently?" If so, how can it be measured? This question may be viewed as a higher cognitive level question than only performance-based "satisfactory/unsatisfactory" evaluation for any given clinical objective at any given time frame using a competency-based model in the case of the entry-level respiratory therapist scope of practice (i.e. metered-dose inhaler, patient assessment, ventilator setup, ventilator management, etc.). The concept of entrusting a learner at a higher level of clinical practice involves many aspects and other intangibles such as behaviors, critical thinking, etc., that may not be part of traditional competency-based training. As ten Cate noted, "EPAs have a holistic nature. They include knowledge, attitude and skill." As an example, the APRT in his or her role as an advanced practice provider would need to provide various skills, attitudes, and competencies to fully assess, provide differential diagnoses, educate, prescribe medication, order diagnostic test, etc., for a patient. APRTs need to also have the cognitive knowledge and skill to perform any procedure or task; however, can APRTs also be trusted to explain the complete task or procedure to a patient or family member and independently counsel them based on medical necessity, benefits and risks? Also, can the APRT be trusted to collaborate with the physician and health care team independently, as well as organize all the processes required for a successful procedure or task outcome? The trust involved in these questions lay outside the traditional arena of competency evaluation, though it is an integral part of the process of ensuring a competent higher-level practitioner 
that can perform and prove themselves to their preceptor from a trust standpoint (i.e. performing a history and physical exam independently, complete with ordering all the needed requirements for care) versus an entry-level practitioner competency in giving a metered-dose inhaler.

EPAs are currently used by the Accreditation Council of Graduate Medical Education as a form of evaluation and assessment of clinical practice. ${ }^{17}$ Traditionally, other health care providers at the advanced practice provider and entry-level incorporate differing variations of the Competency-Based Education concept in clinical education. Recently the health care education community at large has begun to incorporate EPAs for advanced practice providers. For example, nurse practitioners, physician assistants, and pharmacists have also considered and established a framework of EPAs for their respective profession, in addition to higher levels of professional competencies. $^{18-23}$

To develop and teach EPA in respiratory care at the APRT level, the respiratory care education community will need to rethink how it views clinical objectives and competencies at an advanced practice level. The following questions can be asked to find the best method of assessing, evaluating, and entrusting an APRT student and graduate:

1. Would establishing valid and, possibly, standardized assessment tools reflecting a higher level of practice, proficiency, and responsibility be considered?

2. What would be the main EPAs that are expected to be achieved by all APRT graduates?

3. What are the sub-competencies that we expect APRTs to have as part the established EPAs?

Fortunately, the "wheel does not need to be re-invented" in this case to develop EPAs for APRT professionals. When looking at a specialty such as respiratory therapy, and those closely associated in terms of practice and background with cardiopulmonary patients, pulmonary and critical care medicine comes to mind. This profession, pulmonary and critical care medicine specialty have established their own EPAs. ${ }^{24}$ Interestingly, similar concepts are used in both CoARC APRT core competency and pulmonary and critical care fellowship by ACGME (i.e. respiratory and medical knowledge, patient care, professionalism, etc). ${ }^{3,24}$ The only difference in these core competencies is the Inter-professional practice in the CoARC and Practice-based learning and improvement by ACGME.
Although both sets of core-competencies are very similar in terms of the general domain, the difference compared to the pulmonary and critical care group is in other intangible areas of standardized assessment that involve EPAs, such as behaviors and critical thinking. To develop EPAs for APRTs, several attributes and conditions must be met according to ten Cate who established 8 different attributes any EPA must have (i.e. must be essential and critical for professional practice, have an acceptable knowledge and skill, limited to a qualified provider, etc). ${ }^{16}$ These attributes can be used as a foundation to build the additional competencies and sub-competencies and specific APRT EPA attributes.

According to Keene, McHenry, Byington, Washam, ${ }^{4}$ they reported a statistical significance from their respondents in the preference of having an advanced practice provider (nurse practitioner or physician assistant) and/or medical doctor specializing in pulmonary and critical care medicine $(p=0.015)$ as a preceptor/mentor for the APRT student. ${ }^{4}$ Supervising medical doctors currently evaluated their residents using an EPA assessment tool and therefore adding a similar evaluation and assessment tool for APRTs when supervising them as their students/preceptee would be consistent with current practice. In addition, using pulmonary and critical care medicine fellowship EPA's as a foundation that are only based on related knowledge of pulmonary and critical care patients, could be considered as a starting point in developing what the actual EPAs and its sub-competencies for APRT would consist of clinically. Tables 1 and 2 illustrate a sample APRT EPAs developed by the authors and how they line up to currently established EPAs by Fessler $^{24}$ and CoARC core competencies. ${ }^{3}$

In order to implement an EPA to APRT clinical education, a few possible pathways may be considered. First, the accreditation process can approve the use of EPA as the standard evaluation and assessment process across the US. Secondarily, individual programs would establish their own competencies, and EPA outcome assessment based on CoARC APRT standards as a starting point, adding additional programs, as interest and research grows in the profession. Clinical preceptors would need to be educated with the EPA process along with online resources, and media examples. Lastly, consider reviewing and using current advanced practice providers EPA methods and experience as an example, in addition to pulmonary and critical care EPAs. 
Table I This Table Shows a Proposed Sample APRT EPA Attribute That Is Developed by the Authors Derived from Pulmonary and Critical Care Medicine ACGME EPA

\begin{tabular}{|l|l|}
\hline APRT Attribute & APRT EPA Description \\
\hline APRT Attribute I & Manage patients with acute and critical pulmonary diseases across multiple care settings at an advanced provider level, APRT. \\
\hline APRT Attribute 2 & Manage care of patients with chronic, advanced, or end-stage pulmonary diseases at an advanced provider level, APRT. \\
\hline APRT Attribute 3 & Provide consultation to medical team and healthcare providers (physician, nursing, etc). \\
\hline APRT Attribute 4 & Lead multidisciplinary team across multiple medical/healthcare settings at an advanced provider level, APRT. \\
\hline APRT Attribute 5 & $\begin{array}{l}\text { Provide and facilitate learning for patient families and caregivers in different pulmonary and critical care areas as an advanced } \\
\text { provider. }\end{array}$ \\
\hline APRT Attribute 6 & $\begin{array}{l}\text { Assists/perform procedures with physicians in different critical care settings such as ultrasound, bronchoscopy, arterial and } \\
\text { central line placements. }\end{array}$ \\
\hline APRT Attribute 7 & Demonstrate professional behavior with peers, patients, and caregivers. \\
\hline APRT Attribute 8 & Promote and improve the quality and safety of healthcare. \\
\hline
\end{tabular}

Note: Data derived from pulmonary and critical care medicine ACGME EPA in Fessler et al. ${ }^{24}$

Table 2 This Table Shows a Sample EPA That Is Proposed by the Authors and How It Can Be Linked and Associated with the Accrediting Body Core Competency. Each EPA Is Linked with a Specific Core Competency

\begin{tabular}{|c|c|c|c|c|c|c|}
\hline \multirow[t]{2}{*}{ Sample EPA for APRT } & \multicolumn{6}{|c|}{ CoARC APRT Core Competency ${ }^{3}$} \\
\hline & $\begin{array}{l}\text { Respiratory } \\
\text { Care } \\
\text { Knowledge }\end{array}$ & $\begin{array}{l}\text { Interpersonal \& } \\
\text { Communication } \\
\text { Skills }\end{array}$ & $\begin{array}{l}\text { Patient } \\
\text { Care }\end{array}$ & Professionalism & $\begin{array}{l}\text { Systems- } \\
\text { Based } \\
\text { Practice }\end{array}$ & $\begin{array}{l}\text { Inter- } \\
\text { Professional } \\
\text { Practice }\end{array}$ \\
\hline $\begin{array}{l}\text { Manage patients with acute and critical } \\
\text { pulmonary diseases across multiple care } \\
\text { settings at an advanced provider level, } \\
\text { APRT. }\end{array}$ & $x$ & & $x$ & & $x$ & \\
\hline $\begin{array}{l}\text { Manage the care of patients with chronic, } \\
\text { advanced, or end-stage pulmonary } \\
\text { diseases at an advanced provider level, } \\
\text { APRT. }\end{array}$ & $x$ & & $x$ & & $x$ & \\
\hline $\begin{array}{l}\text { Provide consultation to the medical team } \\
\text { and healthcare providers (physician, } \\
\text { nursing, etc). }\end{array}$ & & $x$ & & $x$ & & $x$ \\
\hline $\begin{array}{l}\text { Lead multidisciplinary team across } \\
\text { multiple medical/healthcare settings at an } \\
\text { advanced provider level, APRT. }\end{array}$ & $x$ & $x$ & & $x$ & & $x$ \\
\hline $\begin{array}{l}\text { Provide and facilitate learning for patient } \\
\text { families and caregivers in different } \\
\text { pulmonary and critical care areas as an } \\
\text { advanced provider. }\end{array}$ & $x$ & $x$ & $x$ & $x$ & $x$ & \\
\hline $\begin{array}{l}\text { Assists/perform with physicians different } \\
\text { critical care procedures such as } \\
\text { ultrasound, bronchoscopy, arterial and } \\
\text { central line placements }\end{array}$ & $x$ & $x$ & $x$ & & & $x$ \\
\hline
\end{tabular}


Table 2 (Continued).

\begin{tabular}{|l|l|l|l|l|l|l|}
\hline \multirow{2}{*}{ Sample EPA for APRT } & \multicolumn{3}{|l|}{ CoARC APRT Core Competency } & \multicolumn{3}{l|}{} \\
\cline { 2 - 7 } & $\begin{array}{l}\text { Respiratory } \\
\text { Care } \\
\text { Knowledge }\end{array}$ & $\begin{array}{l}\text { Interpersonal \& } \\
\text { Communication } \\
\text { Skills }\end{array}$ & $\begin{array}{l}\text { Patient } \\
\text { Care }\end{array}$ & Professionalism & $\begin{array}{l}\text { Systems- } \\
\text { Based } \\
\text { Practice }\end{array}$ & $\begin{array}{l}\text { Inter- } \\
\text { Professional } \\
\text { Practice }\end{array}$ \\
\hline $\begin{array}{l}\text { Demonstrate professional behavior with } \\
\text { peers, patients, and caregivers. }\end{array}$ & & $x$ & & $x$ & $x$ \\
\hline $\begin{array}{l}\text { Promote and improve the quality and } \\
\text { safety of healthcare. }\end{array}$ & & & & & $x$ & $x$ \\
\hline
\end{tabular}

\section{Conclusion}

While the journey is only beginning, in terms of developing advanced-level respiratory therapists across the nation, considering such higher-level assessment and evaluation at this inception is key in providing a more competent, entrusted advanced practice providers such as APRT. It is time to consider the development of EPAs in relation to competencies that provide a more robust "standardized framework" in the development of an advance practice provider in the respiratory care profession nationwide. This standardized framework will ensure a consistency in the assessment and evaluation matrix for preceptors of APRTs that is much needed across all accredited programs. While keeping in mind that to achieve best practices, the development of EPAs should not come from one institution or one educator, but from the respiratory care education community at large.

\section{Acknowledgments}

We would like to thank Charles (Bud) Spearman, M.Ed, RRT-FAARC and Dr. Laren D Tan, MD, FCCP for their time reviewing this paper. In addition, special thanks to Professor Andrew Vosko, Ph.D. on his insights regarding Entrustable Professional Activities.

\section{Disclosure}

The authors report no funding and no conflicts of interest in this work.

\section{References}

1. AARC. AARC board moves on key initiatives. Available from: http:// www.aarc.org/aarc-board-moves-on-key-initiatives/. 2016. Accessed February 19, 2019.

2. CoARC. Standards for accreditation of advanced practice programs in respiratory care; 2016. Available from: https://www.coarc.com/Accreditation/ Advanced-Practice-Standards.aspx. Accessed February 16, 2019.

3. CoARC. Accreditation standards for advanced practice programs in respiratory care. 2016; https://www.coarc.com/CoARC/media/Documents/APRTStandards-effective-11-13-16.pdf. Accessed February 19, 2019.
4. Keene S, McHenry K, Byington R, Washam M. Respiratory therapists as physician extenders: perceptions of practitioners and educators. Respir Care Educ Annu. 2015;24:19-27.

5. Douce F, Sergakis G, Dunlevy C, Varekojis S. The need for and interest in the advanced respiratory therapist practitioner. Respir Care Educ Аnпи. 2014;23(Fall 2014):3-7.

6. Fulton JF. History of medical education. $\mathrm{Br}$ Med J. 1953;2 (4834):457-461. doi:10.1136/bmj.2.4834.457

7. Flexner A. The Flexner Report: Medical Education in the United States and Canada. The Carnegie Foundation for the Advancement of Teaching; 1910.

8. Bryan CS. Osler: Inspirations from a Great Physician. New York: Oxford University Press; 1997.

9. Dornan T. Osler, flexner, apprenticeship and 'the new medical education'. J R Soc Med. 2005;98(3):91-95. doi:10.1258/jrsm.98.3.91

10. Team NEJoMK. What is competency-based medical education? $N$ Engl $J$ Med. 2017. Available from: https://knowledgeplus.nejm.org/blog/ what-is-competency-based-medical-education/. Accessed 2018.

11. Nodine T. How did we get here? A brief history of competency-based higher education in the United States. JCBE. 2016;1(1):5-11. doi:10.1002/(ISSN)2379-6154

12. Holmboe ES, Sherbino J, Long DM, Swing SR, Frank JR, Collaborators IC. The role of assessment in competency-based medical education. Med Teach. 2010;32(8):676-682. doi:10.3109/ 0142159X.2010.500704

13. Holmboe ES, Ward DS, Reznick RK, et al. Faculty development in assessment: the missing link in competency-based medical education. Acad Med. 2011;86(4):460-467. doi:10.1097/ACM.0b013e31820cb2a7

14. Carraccio C, Wolfsthal SD, Englander R, Ferentz K, Martin C. Shifting paradigms: from Flexner to competencies. Acad Med. 2002;77(5):361-367. doi:10.1097/00001888-200205000-00003

15. ten Cate O. Nuts and bolts of entrustable professional activities. $J$ Grad Med Educ. 2013;5(1):157-158. doi:10.4300/JGME-D-12-00380.1

16. ten Cate O. Entrustability of professional activities and competencybased training. Med Educ. 2005;39(12):1176-1177. doi:10.1111/ med.2005.39.issue-12

17. Andolsek K, Padmore J, Hauer KE, Edgar L, Holmboe E. Clinical Competency Committees a Guidebook for Programs. 2nd ed. Accreditation Council for Graduate Medical Education: accreditation Council for Graduate Medical Education; 2017.

18. Rugen KW, Speroff E, Zapatka SA, Brienza R. Veterans Affairs interprofessional nurse practitioner residency in primary care: a competency-based program. J Nurse Pract. 2016;12(6):e267-e273. doi:10.1016/j.nurpra.2016.02.023

19. Bargagliotti LA, Davenport D. Entrustables and entrustment: through the looking glass at the clinical making of a nurse practitioner. J Nurse Pract. 2017;13(8):e367-e374. doi:10.1016/j. nurpra.2017.05.018

20. Mulder H, ten Cate O, Daalder R, Berkvens J. Building a competency-based workplace curriculum around entrustable professional activities: the case of physician assistant training. Med Teach. 2010;32(10):e453-e459. doi:10.3109/0142159X.2010.513719 
21. Anthamatten A, Pfieffer ML, Richmond A, Glassford M. Exploring the utility of entrustable professional activities as a framework to enhance nurse practitioner education. Nurse Educ. 2019. doi:10.1097/ NNE.0000000000000697

22. Jarrett JB, Berenbrok LA, Goliak KL, Meyer SM, Shaughnessy AF. Entrustable professional activities as a novel framework for pharmacy education. Am J Pharm Educ. 2018;82(5):6256. doi:10.5688/ ajpe6161
23. Pittenger AL, Chapman SA, Frail CK, Moon JY, Undeberg MR, Orzoff JH. Entrustable professional activities for pharmacy practice. Am J Pharm Educ. 2016;80(4):57. doi:10.5688/ajpe80457

24. Fessler HE, Addrizzo-Harris D, Beck JM, et al. Entrustable professional activities and curricular milestones for fellowship training in pulmonary and critical care medicine: report of a multisociety working group. Chest. 2014;146(3):813-834. doi:10.1378/chest.14-0710

\section{Publish your work in this journal}

Advances in Medical Education and Practice is an international, peerreviewed, open access journal that aims to present and publish research on Medical Education covering medical, dental, nursing and allied health care professional education. The journal covers undergraduate education, postgraduate training and continuing medical education including emerging trends and innovative models linking education, research, and health care services. The manuscript management system is completely online and includes a very quick and fair peer-review system. Visit http://www.dovepress.com/testimonials.php to read real quotes from published authors.

Submit your manuscript here: http://www.dovepress.com/advances-in-medical-education-and-practice-journal 